\section{Prognostic Value of Bone Scintigraphy in Cancer Patients With Osteonecrosis of the Jaw Is There Something Missing?}

\section{To the Editor:}

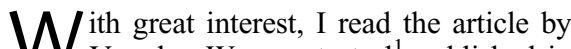
Van den Wyngaert et $\mathrm{al}^{1}$ published in Clinical Nuclear Medicine (2011;36:17-20). Better late than never.

The authors reported on the potential detection of bisphosphonate osteonecrosis of the jaw (BP ONJ) using bone scintigraphy. They performed planar bone scintigraphy and SPECT in 22 patients with stage 1 to 3 BP ONJ and postulated that SPECT will detect BP ONJ lesions and provide prognostic information.

Apart from the very limited number of patients and sample power, there is something missing in the interpretation of results, which, in my opinion, ought to be resolved.

Bone scintigraphy as such, including SPECT acquisition, represents a surrogate parameter reflecting osteoblasts' activity by tracer uptake in ROI. This is, in turn, the hallmark of osteomyelitic changes or a sign of reparative process after trauma, surgery, and bone remodeling. $^{2-4}$

Although the pathogenesis of BP ONJ is not yet completely understood, it is assumed that this condition is related to alteration of bone remodeling because of the inhibition of osteoclast function and bone turnover. ${ }^{5}$

Taking these aspects into consideration, the findings presented in this study are "nonspecific" in the sense of not being related to osteonecrosis, which is "invisible" by bone scintigraphy, but to the more or less associated osteomyelitic lesion or reparative process. This is, at the same time, the simple explanation of the inhomogeneous distribution of scintigraphic findings among the 3 groups, namely the lesions induced various types of inflammatory and reparative changes in the affected bone.

I found the article by Van den Wyngaert et al very interesting; apparently, the reviewer did so too. However, I missed this critical aspect in the discussion and had to make up for the readers of Clinical Nuclear Medicine.

Samer George Hakim, MD, DMD, PhD Department of Oral and Maxillofacial Surgery University of Luebeck Luebeck, Germany samer.hakim@mkg-chir.mu-luebeck.de

\section{REFERENCES}

1. Van den Wyngaert T, Huizing MT, Fossion E, et al. Prognostic value of bone scintigraphy in cancer patients with osteonecrosis of the jaw. Clin $\mathrm{Nucl}$ Med. 2011;36:17-20.

2. Hakim SG, Bruecker CW, Jacobsen H, et al. The value of FDG-PET and bone scintigraphy with SPECT in the primary diagnosis and follow-up of patients with chronic osteomyelitis of the mandible. Int J Oral Maxillofac Surg. 2006;35:809-816.

3. Mader JT, Shirtliff M, Calhoun JH. Staging and staging application in osteomyelitis. Clin Infect Dis. 1997;25:1303-1309.

4. Schauwecker DS. The scintigraphic diagnosis of osteomyelitis. AJR Am J Roentgenol. 1992;158: 9-18.

5. Rogers MJ, Gordon S, Benford HL, et al. Cellular and molecular mechanisms of action of bisphosphonates. Cancer. 2000;88:2961-2978.

\section{Macroaggregated Albumin (MAA) Injected in Hepatic Artery Visualized in a Recanalized Paraumbilical Vein}

\section{To the Editor:}

read the article titled "Macroaggregated albumin (MAA) injected in hepatic artery visualized in a recanalized paraumbilical vein" by Gupta et al ${ }^{1}$ with great interest. Localization mechanism of ${ }^{99 \mathrm{~m}} \mathrm{Tc}$-MAA is related to the particle size of MAA (usually $30-50 \mu \mathrm{m})$, which is larger than the size of the capillary. When the particles infused into the hepatic artery, they distribute according to blood flow and are trapped on first pass in the arteriolar-capillary bed of the liver. Therefore, the ${ }^{99 \mathrm{~m}}$ Tc-MAA hepatic arterial scintigraphy can help to determine the possibility and amount of extrahepatic perfusion by intrahepatic infusion of ${ }^{90} \mathrm{Y}$ microspheres, which gives rise to systemic toxicity.

The report by Hsieh et al, ${ }^{2}$ introduced on the interesting image, had demonstrated visualization of the portosystemic collateral circulation with ${ }^{99 \mathrm{~m}} \mathrm{Tc}$ RBC scintigraphy and it is natural because of the localization mechanism of ${ }^{99 \mathrm{~m}} \mathrm{Tc}$ RBC in blood vessels. The case report by Chernyak et al ${ }^{3}$ visualized focal tracer uptake at the abdominal wall with ${ }^{99 \mathrm{~m}}$ Tc-MAA scintigraphy. It might be possible by ${ }^{99 \mathrm{~m}} \mathrm{Tc}-\mathrm{MAA}$ accumulation in a small area of the abdominal wall by its possible blood supply from the patent hepatic falciform artery.

Owing to the localization mechanism of the ${ }^{99 \mathrm{~m}}$ Tc-MAA particle, the particles which arrived at paraumbilical vein should flow away to next arteriolar-capillary beds.
Therefore, an uptake mechanism of the ${ }^{99 \mathrm{~m}} \mathrm{Tc}$ MAA at the recanalized large paraumbilical vein on the SPECT imaging of the interesting image is not obvious and hard to be conjectured. Readers of the interesting image might be more curious about the reason of MAA retention in the paraumbilical vein, and hopefully, it will be answered or suggested by the authors.

Byeong-Cheol Ahn, MD, PhD Department of Nuclear Medicine Kyungpook National University School of Medicine and Hospital Daegu, South Korea abc2000@knu.ac.kr

\section{REFERENCES}

1. Gupta A, Levitin A, Shrikanthan S. Macroaggregated albumin injected in hepatic artery visualized in a recanalized paraumbilical vein. Clin Nucl Med. 2012;37:80-81.

2. Hsieh HJ, Lue $\mathrm{KH}$, Kao $\mathrm{CH}$, et al. Portosystemic collateral circulation: demonstrated by Tc- $99 \mathrm{~m}-$ RBC SPECT/CT. Clin Nucl Med. 2009;34:958-959.

3. Chernyak I, Bester L, Freund J, et al. Anterior abdominal wall uptake in intrahepatic arterial brachytherapy with yttrium-90 sir spheres for hepatic malignancy. Clin Nucl Med. 2008;33:677-680.

\section{Myocardial Perfusion Scintigraphy After Cardiac Arrest: On the Pathophysiology of Cardiac Death}

\section{To the Editor:}

ima et $\mathrm{al}^{1}$ presented a 74-year-old man L who showed extensive ischemia associated with cardiac arrest during exercise stress myocardial perfusion scintigraphy (MPI). The authors concluded that MPI after cardiac arrest is able to illustrate the pathophysiology of cardiac death.

To expand further on this point, we would like to add a rare experience in which MPI was able to show the consequence of cardiac death during cardiac arrest.

This is a 48-year-old woman who was referred to our department to be assessed for coronary artery disease. She had been hospitalized because of diabetic foot. She also had a history of hypertension. 

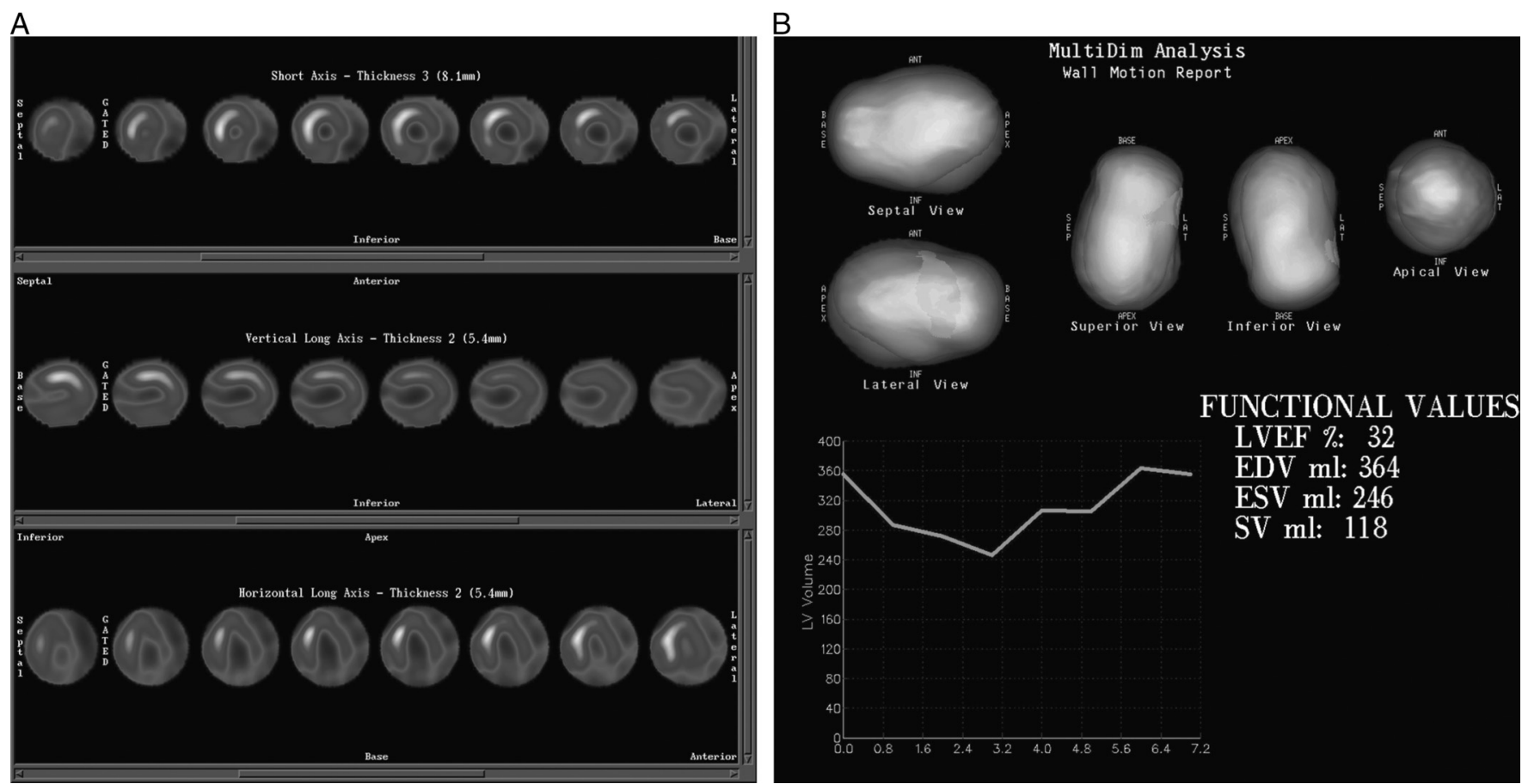

FIGURE 1. A and B, Dipyridamole ${ }^{99 \mathrm{~m}}$ TC-MIBI MPI SPECT images of a 48-year-old patient showing severe perfusion defects in the most left ventricle segments. Just the septal and anteroseptal walls were preserved.

The patient underwent dipyridamole ${ }^{99 \mathrm{~m}} \mathrm{Tc}$ followed by gated myocardial perfusion imaging (MPI) 90 minutes later. During image acquisition (at frame 59 of 64), she showed cardiac arrest with asystolic cardiac rhythm. Cardiopulmonary resuscitation was started immediately, and it was successful.

The MPI showed decreased perfusion of most left ventricle segments and just preserved septal and anteroseptal walls (Fig. 1).

This is a rare report of cardiac arrest 1.5 hours after dipyridamole stress, which was recorded by a gamma camera.
This report emphasized the unique role of MPI in showing real-time cardiac arrest. In addition, it depicted the value of patient monitoring during the recovery period even after dipyridamole stress.

Hamid Javadi, MD Golestan Research Center of Gastroenterology and Hepatology Golestan University of Medical Sciences Gorgan, Iran
Majid Assadi, MD The Persian Gulf Nuclear Medicine Research Center Bushehr University of Medical Sciences Bushehr, Iran assadipoya@yahoo.com, asadi@bpums.ac.ir

\section{REFERENCE}

1. Lima RS, De Lorenzo A, Nobrega B, et al. Myocardial perfusion scintigraphy after cardiac arrest: on the pathophysiology of cardiac death. Clin Nucl Med. 2012;37:387-389. 